\title{
Early Childhood Adversities and Trajectories of Psychiatric Problems in Adoptees: Evidence for Long Lasting Effects
}

\author{
Esther J. M. van der Vegt • Jan van der Ende • \\ Robert F. Ferdinand - Frank C. Verhulst • \\ Henning Tiemeier
}

Published online: 20 September 2008

(C) The Author(s) 2008. This article is published with open access at Springerlink.com

\begin{abstract}
The aim of the present study is to investigate whether early childhood adversities determine the longitudinal course of psychiatric problems from childhood to adulthood; in particular if the impact of early maltreatment on psychopathology decreases as time passes. A sample of 1,984 international adoptees was followed (955 males and 1029 females; adopted at the mean age of 29 months). Parents provided information about abuse, neglect and number of placements prior to adoption at baseline and completed the Child Behavior Checklist or the Young Adult Behavior Checklist three times when their children were between 10 and 30 years of age. Multilevel analyses were performed to determine trajectories of psychiatric problems. Experience of early childhood adversity prior to adoption substantially increased the level of psychiatric problems, especially when maltreatment was severe. Moreover, the impact of early adversities on psychiatric problems remained markedly stable. This suggests that vulnerability of early-maltreated children persists even if they are taken out of their problematic environments and are raised in enriched circumstances.
\end{abstract}

Keywords Childhood maltreatment - Trajectories . Internalizing $\cdot$ Externalizing $\cdot$ International adoption

Several studies have reported that children who have experienced early childhood adversities, such as abuse or neglect, are at an increased risk for psychiatric problems in

E. J. M. van der Vegt • J. van der Ende • R. F. Ferdinand •

F. C. Verhulst $\cdot H$. Tiemeier $(\square)$

Department of Child and Adolescent Psychiatry,

Erasmus MC-Sophia Children's Hospital,

P.O. Box 2060, 3000 CB Rotterdam, The Netherlands

e-mail: h.tiemeier@erasmusmc.nl childhood, adolescence or adulthood (see for reviews: Trickett and McBride-Chang 1995; Tyler 2002). However, in many of these previous studies, it is hard to determine the specific effects of maltreatment experienced early in life. Early childhood adversities commonly co-occur with other risk factors for later psychiatric problems, such as low socioeconomic status and inadequate family functioning (Costello et al. 2003; Fergusson et al. 1996; Horwitz et al. 2001; Hudson 2005; Kessler et al. 1997; Mullen et al. 1996). Children who experience early adversities often continue to live within these risk-increasing environments. Although a few studies tried to control for these confounding effects (e.g., Fergusson et al. 1996), most previous studies investigated the effects of chronic adversities.

An internationally adopted sample can provide an opportunity to study the specific effects of early childhood adversities. International adoptees are at risk for maladjustment because of several pre- and perinatal factors, for example maternal stress during pregnancy and inadequate medical care, as well as factors operating after birth, such as malnutrition and maternal separation. Furthermore, many international adoptees experienced early maltreatment (Gunnar et al. 2000; Verhulst et al. 1992), but they were subsequently taken out of their problematic environment in childhood and raised in enriched circumstances. Previous studies in internationally adopted samples demonstrated effects of early adversities on mental health problems in childhood, adolescence or adulthood (e.g., Cederblad et al. 1999; Fensbo 2004; Fisher et al. 1997; Hoksbergen 1997; Juffer and Van IJzendoorn 2005; Marcovitch et al. 1997; Verhulst et al. 1992). These internationally adopted samples comprised children from several countries. For example, Cederblad et al. (1999), using an international adoptees sample in Sweden, showed an association between duration of care in an orphanage or foster home and mental health 
problems. The majority of the children came from Korea, India, and Colombia. In a study conducted in The Netherlands, Hoksbergen (1997) found that there was an increased risk of disruption and residential care in children adopted from Thailand, who had lived in an orphanage or had experienced several changes of caretaking places. Similarly, in an earlier report of the present sample, number of changes of caretaking environment, neglect, physical health and especially abuse increased the risk of mental health problems in the international adoptees aged between 10 and 15 years (Verhulst et al. 1992). Preplacement situations can be quite diverse according to the home country. For example, most adopted children from Asia were only a few months old at adoption and many children from Eastern Europe had been living in overcrowded orphanages for years (Fensbo 2004). Furthermore, in domestic US adoptions, a relationship between early adversities and behavior problems later in life was found (Simmel 2007; Simmel et al. 2007).

Although effects of early childhood adversities are found later in life, there is some indication that the impact of early maltreatment on psychiatric problems decreases as time passes. In a group of Romanian children who experienced early institutional deprivation and were adopted into the UK at an early age, considerable developmental catch-up was seen in childhood after adoption (Beckett et al. 2002; Rutter and the ERA Study Team 1998). Improvements were seen in specific areas, for example in height, growth, cognitive level and atypical behavior (Beckett et al. 2002; Beckett et al. 2006; Rutter and the ERA Study Team 1998). Surprisingly, there was an increase in emotional and behavioral disturbances in the adopted group. However, there was no clear association between early deprivation and emotional or behavioral problems (Colvert et al. 2008; Kreppner et al. 2007; Rutter et al. 2001). Furthermore, in a cross-sectional study of a non-adopted sample, Kessler et al. (1997) found that the risk of psychiatric disorder onset was highest during the first few years after the occurrence of a childhood adversity. The risk declined within approximately a decade to a level equivalent to that found among people who were not exposed. However, Kessler and colleagues did not focus on childhood adversities experienced early in life. In a longitudinal study, Thornberry et al. (2001) studied participants who experienced adversities before the age of 5 years and observed few problems in early adolescence (age 14-16 years) and even less problems in late adolescence (age 16-18 years). Another indication for a decrease in the impact of adversities can be found in studies of life events. Obviously, life events encompass more than early adversities, but it is noteworthy that the effects of life events on anxiety and mood disorders diminish within a few months to years (Hillegers et al. 2004; Surtees and Wainwright 1999).
Several studies on non-adopted samples have used repeated measures to study the effects of childhood adversities on the developmental course of psychiatric problems. Mostly, lasting effects were found (e.g. Cicchetti and Rogosch 1997; Éthier et al. 2004; Keiley et al. 2001; Lansford et al. 2006), although not always (Thornberry et al. 2001). However, many of these studies were not able to fully control the effects of chronic adversities. Furthermore, these studies investigated effects from childhood into adolescence only and did not cover adulthood. In addition, some cross-sectional studies but not others reported an influence of gender on the effect of maltreatment (Trickett and McBride-Chang 1995; Tyler 2002). To our knowledge, modification by gender has not yet been investigated within studies on the longitudinal course of psychiatric problems due to early adversities. However, in the general population, psychiatric problems, as well as their longitudinal course differ strongly according to gender (Bongers et al. 2003). The vulnerability to develop psychiatric problems after the experience of early adversities might also differ between males and females. The aim of the present study is to investigate how early childhood adversities influence the development of psychiatric problems from childhood into adulthood in an internationally adopted sample. We hypothesize that early adversities have a substantial impact on externalizing and internalizing behavior but that this impact decreases over long periods of time. We expect this change with time firstly, because adversities were restricted to a certain life period and, secondly, because there is a long period between the experience of adversities and the measurement of psychiatric problems. Additionally, we want to study whether developmental trajectories of psychiatric problems in individuals who experienced early childhood adversities depend on gender.

\section{Method}

Sample and Procedure

For the original sample, children were selected from the central adoption register of the Dutch Ministry of Justice. The sample consisted of all children $(N=3,519)$ legally adopted by nonrelatives in the Netherlands and born outside The Netherlands between January 1, 1972, and December 31, 1975. Most children were adopted from developing countries such as Korea, Colombia, India, Indonesia, and Bagladesh. Prior to adoption, many of the participants lived under dreadful circumstances. For example, several adoptees had been extremely malnourished, suffered from severe physical diseases or had received hardly any emotional warmth. In 1986, the parents of the international adoptees were approached for the first time. 
Of the 3,309 parents who could be reached, 2,148 participated in the study $(64.9 \%)$ at baseline. Ages of the adopted children were between 10 and 15 years. Details on the initial sampling procedure are reported elsewhere (Verhulst et al. 1990).

The sample was approached again in 1989-1990 (time 2) except for 77 children (three children had died, eight had moved abroad, 29 were untraceable, and 37 participated in another academic study). The remaining parents of 2,071 children were contacted; of these, 1,538 participated (74.3\% of eligible; $71.6 \%$ of baseline). For details on the second measurement, see Verhulst and Versluis-den Bieman (1995).

Between 1999 and 2002, the 2,148 adoptees themselves were contacted again (time 3), with the exception of 263 adoptees (15 had died, 72 had emigrated, 59 were untraceable, 13 were mentally retarded, 100 had requested at previous stages to be removed form the sample, and four were unaware that they were adopted). Of the 1,885 remaining adoptees, 1,521 participated $(80.7 \%$ of eligible; $70.8 \%$ of baseline). Adoptees were asked for permission to contact their adoptive parents. Of the 1,358 parents that were approached, 1,157 participated $(85.2 \%$ of eligible; $53.9 \%$ of baseline). More information regarding the sampling procedure at time 3 can be found elsewhere (Tieman et al. 2005, 2006).

The University Hospital Medical Ethical Committee approved the study and after the procedures were fully explained, informed consent was obtained from all participants. At baseline, adoptive parents filled out questionnaires about early childhood adversities prior to adoption and demographical variables. During all measurements, psychiatric problems were assessed using parental questionnaires. At time 3, a subsample of international adoptees filled out questionnaires about social functioning $(N=$ $1,417)$ and psychiatric problems $(N=1,046)$. In the present study, participants were excluded if information on all early childhood adversities was missing or uncertain $(N=164)$. Of the 1,984 participants who remained for analyses, 848 parents participated three times, 746 parents participated two times, and 390 parents participated only one time. Figure 1 shows a flow diagram of the response in the present study. For characteristics on the participants, see Table 1.

Measures

\section{Early Childhood Adversities}

At baseline, adoptive parents were asked about abuse, neglect and number of placements of their children prior to adoption and its severity using single questions. The Dutch term used in the question about abuse does not cover sexual

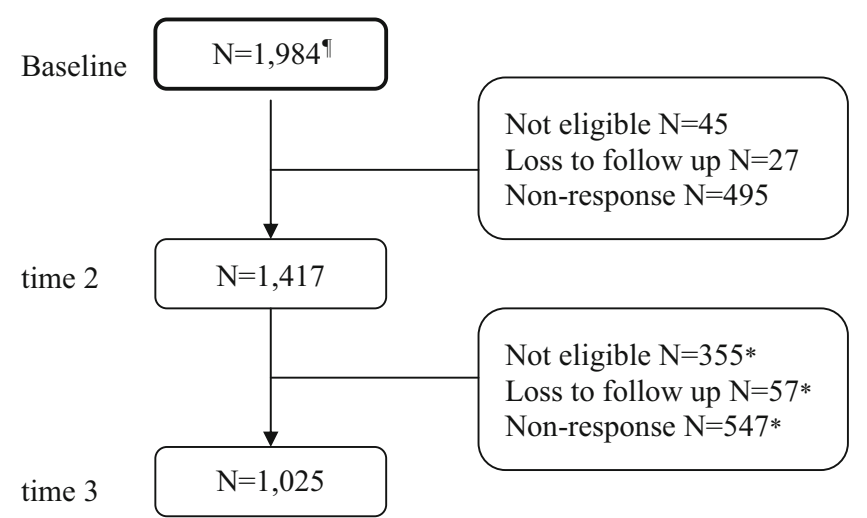

Fig. 1 Diagram of the number of adoptees of which parents provided information about psychiatric problems. I Because of missing information on all early adversities, we included 1,984 adoptees in one or more analyses. The total sample consisted of 2,148 adoptees. * At time 3 all 1,984 adoptees, whose parents participated at baseline, were approached and asked for permission to contact their adoptive parents

or emotional abuse equally well as physical abuse. Thus, although other forms of abuse were not ruled out, abuse encompassed mainly physical abuse. Neglect was specified as physical neglect. Abuse and neglect were measured using a 3-point scale indicating "no", "somewhat", or "severe" abuse or neglect. Number of placements was assessed on a 4 -point scale with answering categories " 0 ", " 1 or 2 ", "3 or 4 " or " 5 or more" changes in caretaking environment prior to adoption. Because of a small number of cases, the third and fourth categories were combined in the analyses into " 3 or more" placements. Frequently, information on early adverse experiences is missing or uncertain (Fensbo 2004; Verhulst et al. 1992). Therefore, we asked adoptive parents if they were certain of their answer after every question on an early adversity. In our analyses only information of which parents were certain was used. Parents based their information on maltreatment on official documents provided by the adoption organization or on the conditions of life in the country of origin or the state of the child directly after adoption. Furthermore, the prospective validity of the severity of maltreatment was demonstrated in a previous study on the same sample that showed a relationship between the level of early maltreatment and the level of later maladjustment (Verhulst et al. 1992).

\section{Psychiatric Problems}

It is a well-known fact that the consistency in measuring psychiatric problems between different raters and different instruments is poor (e.g., Van der Ende 1999). Therefore, to study the longitudinal course of psychiatric problems from childhood onwards, we used the same rater and similar rating scales. 
Table 1 Characteristics of the Participants $(N=1,984)$

\begin{tabular}{|c|c|}
\hline Characteristics & Values \\
\hline Gender, $N(\%)$ male & $955(48.1)$ \\
\hline $\mathrm{Age}^{\mathrm{a}}$, mean in years $\pm \mathrm{SD}$ & $12.4 \pm 1.2$ \\
\hline \multicolumn{2}{|l|}{ Parental socioeconomic status ${ }^{\mathrm{a}}$} \\
\hline Low, $N(\%)$ & $178(9.0)$ \\
\hline Middle, $N(\%)$ & $523(26.4)$ \\
\hline High, $N(\%)$ & $1,283(64.7)$ \\
\hline Age at placement, mean in months \pm SD (range) & $29.0 \pm 25.0(1-115$ \\
\hline \multicolumn{2}{|l|}{ Countries of origin } \\
\hline Korea, $N(\%)$ & $615(31.0)$ \\
\hline Colombia, $N(\%)$ & $275(13.9)$ \\
\hline India, $N(\%)$ & $192(9.7)$ \\
\hline Indonesia, $N(\%)$ & $163(8.2)$ \\
\hline Bangladesh, $N(\%)$ & $126(6.4)$ \\
\hline Lebanon, $N(\%)$ & $104(5.2)$ \\
\hline Austria, $N(\%)$ & $106(5.3)$ \\
\hline Other European countries, $N(\%)$ & $90(4.5)$ \\
\hline Other non-European countries, $N(\%)$ & $313(15.8)$ \\
\hline \multicolumn{2}{|l|}{ Abuse } \\
\hline None, $N(\%)$ & $1,269(64.0)$ \\
\hline Some, $N(\%)$ & $120(6.0)$ \\
\hline Severe, $N(\%)$ & $57(2.9)$ \\
\hline Missing or uncertain, $N(\%)$ & $538(27.1)$ \\
\hline \multicolumn{2}{|l|}{ Neglect } \\
\hline None, $N(\%)$ & $928(46.8)$ \\
\hline Some, $N(\%)$ & $455(22.9)$ \\
\hline Severe, $N(\%)$ & $305(15.4)$ \\
\hline Missing or uncertain, $N(\%)$ & $296(14.9)$ \\
\hline \multicolumn{2}{|l|}{ Placements } \\
\hline None, $N(\%)$ & $706(35.6)$ \\
\hline 1 or $2, N(\%)$ & $766(38.6)$ \\
\hline 3 or more, $N(\%)$ & $90(4.5)$ \\
\hline Missing or uncertain, $N(\%)$ & $422(21.2)$ \\
\hline \multicolumn{2}{|l|}{ Marital status ${ }^{\mathrm{b}}$} \\
\hline Married, $N(\%)$ & $198(14.0)$ \\
\hline Divorced, $N(\%)$ & $14(1.0)$ \\
\hline Unmarried, $N(\%)$ & $1,201(85.0)$ \\
\hline Relationship $^{\text {b }}(>1$ year), $N(\%)$ & $773(54.6)$ \\
\hline Paid labor ${ }^{\mathrm{b}}, N(\%)$ & $1,060(74.9)$ \\
\hline Relationship with friends ${ }^{\mathrm{b}}$, mean $\pm \mathrm{SD}$ (range) & $10.5 \pm 2.9(7-21)$ \\
\hline
\end{tabular}

$S D$ standard deviation

${ }^{a}$ Age and parental socioeconomic status at baseline

${ }^{\mathrm{b}}$ These characteristics were not applicable at baseline, information is available for marital status: $N=1,413$; relationship: $N=1,417$; paid labor: $N=1,415$; and relationship with friends: $N=1,376$

The Child Behavior Checklist (Achenbach 1991) is a parent questionnaire for assessing emotional and behavioral problems in children aged 4 to 18 years old, which was used at baseline and time 2 . The questionnaire contains 118 problem items on which parents can score their child's behavior in the preceding six months according to the categories "not true", "somewhat or sometimes true", "very true or often true". Scores can be added to obtain eight syndrome scales and two broadband clusters of syndromes: Internalizing (consisting of the Anxious/Depressed, Somatic Complaints and Withdrawn scales) and Externalizing (consisting of the Aggressive Behavior and Delinquent Behavior scales). The good reliability and validity of the American version of the CBCL were confirmed for the Dutch translation (Achenbach 1991; Verhulst et al. 1996).

At time 3, the Young Adult Behavior Checklist (Achenbach 1997) was used, which is an upward extension of the CBCL on which parents can report on the 6 months prevalence of emotional and behavioral problems of their children aged 18 to 30 years old. The response format is similar to that of the CBCL and scores can be added into eight syndrome scales and two broadband clusters of syndromes: Internalizing (consisting of the Anxious/ Depressed and Withdrawn scales) and Externalizing (consisting of the Intrusive Behavior, Delinquent Behavior and Aggressive Behavior scales). Achenbach (1997) reported a good reliability and validity for the American YABCL, while for the Dutch YABCL an average Cronbach's $\alpha$ across syndromes of 0.81 was found in a referred sample (Heijmens Visser et al. 2000).

Adoptees themselves filled out the Young Adult SelfReport (YASR; Achenbach 1997), a comparable questionnaire $(N=1,046)$.

In the analyses, scores on the Internalizing and Externalizing scales were used, which were computed omitting items that were not included in both the CBCL and YABCL. Furthermore, for additional analyses, we also calculated syndrome scales using the same procedure.

\section{Demographic Variables}

At baseline, gender, age (in years), age of placement in the adoptive family (in months), country of origin and parental socioeconomic status of the child were derived. Following the method of Van Westerlaak et al. (1975), parental socioeconomic status was measured on a 6-point scale and collapsed into three categories: low, middle and high.

\section{Social Functioning}

At time 3 , in a subsample of the international adoptees $(N=$ 1,417), marital status (married, divorsed or unmarried), relationship (defined as a relationship which had lasted for at least a year) and primary occupation (paid labor or no paid labor) were assessed. Furthermore, social functioning with friends was assessed by the subscale: "relationship with friends" of the Groningen Questionnaire about Social Behavior (GQSB; De Jong and Van der Lubbe 2001; Van der Lubbe 1995). The validity, test-retest reliability and internal consistency of this scale are good (De Jong and Van der Lubbe 2001; Van der Lubbe 1995). 


\section{Selective Attrition}

The total sample consisted of 2,148 adoptees. Because of missing or uncertain information on all early adversities, we included 1,984 adoptees in one or more analyses. We tested the differences between these 1,984 included participants and the 164 individuals for whom information on all early childhood adversities was missing or uncertain. With respect to gender, age and parental socioeconomic status no differences were found. However, those with uncertain or missing information on all early adversities had more psychiatric problems at baseline (CBCL: Internalizing problems: mean $=4.9, \mathrm{SD}=4.4$, versus mean $=4.0, \mathrm{SD}=$ 4.3, $t(2,146)=-2.5, p<0.05$; Externalizing problems: mean $=$ 7.7, $\mathrm{SD}=8.0$, versus mean $=6.1, \mathrm{SD}=7.1, t(184.5)=-2.4$, $p<0.05)$ in comparison to included participants. Furthermore, adoptees for whom information was uncertain or missing were on average almost nine months older at placement in their adoption family than individuals who were included in the study (mean $=37.6, \mathrm{SD}=19.8$, versus mean $=29.0, \mathrm{SD}=25.0, t(2,086)=-5.3, p<0.001)$.

\section{Statistical Analyses}

Using the same rater and similar rating scales at the three time points, resulted in information exclusively derived from parents. Because doubts have been raised about the accurateness of mental health problems assessed by the parent, specifically in older age groups, we correlated the YABCL scores to YASR scores, obtained from the adoptees themselves $(N=1,046)$.

To determine the effects of early childhood adversities on the course of psychiatric problems multilevel analyses were performed (e.g., Boyle and Willms 2001). In multilevel analyses nested data are used. In the present study, repeated measures of psychiatric problems (level 1) are nested within the individual (level 2). Each individual is allowed its own trajectory, which can be summarized for groups of individuals. In this study, trajectories of problem scores are determined for groups of individuals who have experienced a certain degree of an early adversity. An additional benefit of the multilevel analyses is the possibility to use information on adoptees with missing data on one or two time points.

We performed multilevel analyses using the MIXED procedure in SPSS 12.0. We generated six multilevel models with one of the three early adversities as predictor and Internalizing or Externalizing problems as the outcome, following the same procedure. The curves were fitted with random effects for both intercept and age. Furthermore, the models included the following parameters: early adversity, age, age of placement, country of origin, gender, socioeconomic status, early adversity $\times$ age, age $\times$ gender and $a^{2} e^{2}$. Custom Hypotheses Tests were used to investigate differ- ences in height and shape of the trajectories. Post hoc analyses were performed using syndrome scales as outcome variables to find possible differences in the shape of the trajectories. Figures were constructed using the Estimated Means procedure. Bonferonni corrections were used to take into account the effect of multiple testing.

Furthermore, the modifying effect of gender was studied by additionally including the following interaction effects in the models: early adversity $\times$ gender and age $\times$ early adversity $\times$ gender.

We additionally adjusted the analyses for social functioning, i.e. marital status, relationship that has lasted for at least a year, primary occupation and the relationship with friends. Because these measures were not applicable at baseline due to the age of the adoptees, these data was only available in adult participants in the last examination. We checked their potential confounding effect by comparing estimate changes, but we did not include these covariates in our core models due to missing data.

\section{Results}

To strengthen the assumption that parent reports are a valid measure for mental health problems, we correlated the scores on the parental reports and the scores obtained from the adoptees themselves. There is a statistically significant relationship between the YABCL scores and the YASR scores, $r(1,044)=0.42, p<0.01$.

Abuse, neglect and, to a lesser extent, number of placements all contributed significantly to the final models. In other words, early adversities determined the levels of Internalizing and Externalizing psychiatric problems. However, changes in the level of psychopathology over time could not be ascribed to the experience of early adversities. Furthermore, trajectories were fairly similar across gender. The parameters of the main and interaction effects of each early adversity and age within the multilevel models are shown in Tables 2, 3 and 4. Figures 2 and 3 depict the impact of abuse and neglect on the trajectories of Internalizing and Externalizing problems, keeping all other main and interaction effects in the final models constant.

In Table 2 the final model for the longitudinal course of the impact of abuse on Internalizing and Externalizing problems is presented. Across the age span, somewhat or severely abused males or females had higher levels of Internalizing problems than non-abused males or females [respective estimates (standard error, $\mathrm{SE}$ ) and $p$ values: 1.44 (0.45), $p=0.001$ and $2.21(0.64), p=0.0005]$. Similar differences in Externalizing problems were found between somewhat or severely abused and non-abused participants [respective estimates (SE) and $p$-values: $2.61(0.72), p=$ 0.0003 and 3.48 (1.00), $p=0.0005]$. Furthermore, a signif- 
Table 2 The Impact of Abuse on Trajectories of Psychiatric Problems

\begin{tabular}{llll}
\hline & & Internalizing problems-estimates (SE) & Externalizing problems-estimates (SE) \\
\hline Abuse & No & Ref. & Ref. \\
& Some & $1.44^{* *}(0.45)$ & $2.61^{* * *}(0.72)$ \\
& Severe & $2.21^{* * *}(0.64)$ & $3.48^{* * *}(1.00)$ \\
Age & & $0.37^{* * *}(0.050)$ & $0.38^{* * *}(0.069)$ \\
Abuse $\times$ age & No $\times$ age & Ref. & Ref. \\
& Some $\times$ age & $-0.030(0.044)$ & $0.021(0.052)$ \\
& Severe $\times$ age & $-0.017(0.069)$ & $0.0041(0.082)$ \\
\hline
\end{tabular}

From the final multilevel models, fixed parameters of main and interaction effects of abuse and age are shown, as well as the accompanying main factor in the interaction. Other parameters of the final models are not presented $S E$ Standardized error

${ }^{*} p<0.05, * * p<0.01, * * * p<0.001$

icant interaction effect was seen between abuse and gender with regard to the risk of Externalizing problems. When we compared severely abused males with males who were moderately abused, we found a significant difference in Externalizing problems [estimate (SE) and $p$-value: 4.50 (1.71), $p=0.009]$. The difference between somewhat and severely abused males was not observed in females [estimate (SE) and $p$ value: -1.91 (1.56), $p=0.22$ ].

Table 3 presents the effect of neglect on psychiatric problems. Severely neglected adoptees experience more Internalizing problems as well as Externalizing problems throughout the age span in comparison to persons who were not neglected [respective estimates (SE) and $p$-values: 1.11 (0.27), $p=0.0004$ and 3.03 (0.51), $p=0.000000003]$. The difference between somewhat abused and non-abused participants was not significant. No differences were found according to gender. The impact of the number of placements on psychiatric problems is given in Table 4. The levels of Internalizing problems are higher when children experience three or more placements prior to adoption in comparison to no placements [estimate (SE) and $p$ value: $1.11(0.54), p=0.04]$. However, one or two placements were not associated with more Internalizing problems and multiple placements were not related to Externalizing problems at all. No gender differences were found.

Shapes of trajectories of Internalizing or Externalizing problems did not differ significantly according to the experience of early adversities; that is, there was no significant interaction between early adversities and age. Furthermore, no differences between men and women were found in the shapes of trajectories of Internalizing or Externalizing problems according to the experience of early adversities. Because we performed multiple primary analyses, we tested if effects were still significant after a Bonferonni correction. All findings remained significant, except for the relationship between three or more placements and Internalizing problems.

In additional analyses we studied whether age modified the effect of the three early adversities on a subscale level of the CBCL and YABCL. We were able to test developmental trajectories using multilevel analyses of the seven analogous subscales because of similar concepts, omitting items that were not included in the CBCL and YABCL. Three interaction terms between an early adversity and psychiatric problems reached significance. Differences were seen between trajectories of Thought problems and Attention problems, according to the

Table 3 The Impact of Neglect on Trajectories of Psychiatric Problems

\begin{tabular}{llll}
\hline & & Internalizing problems_estimates (SE) & Externalizing problems-estimates (SE) \\
\hline Neglect & No & Ref. & Ref. \\
& Some & $0.38(0.27)$ & $0.85(0.44)$ \\
& Severe & $1.11 * * *(0.31)$ & $3.03 * * *(0.51)$ \\
Age & & $0.40^{* * *}(0051)$ & $0.44 * * *(0.069)$ \\
Neglect $\times$ age & No $\times$ age & Ref. & Ref. \\
& Some $\times$ age & $0.0073(0.026)$ & $0.046(0.032)$ \\
& Severe $\times$ age & $0.018(0.031)$ & $-0.000052(0.038)$
\end{tabular}

From the final multilevel models, fixed parameters of main and interaction effects of neglect and age are shown, as well as the accompanying main factor in the interaction. Other parameters of the final models are not presented

$S E$ Standardized error

${ }^{*} p<0.05,{ }^{* *} p<0.01, * * * p<0.001$ 
Table 4 The Impact of Placements on Trajectories of Psychiatric Problems

\begin{tabular}{llll}
\hline & & Internalizing problems-estimates (SE) & Externalizing problems-estimates (SE) \\
\hline Placements & No & Ref. & Ref. \\
& 1 or 2 & $0.30(0.25)$ & $0.20(0.40)$ \\
Age & 3 or more & $1.11^{*}(0.54)$ & $1.68(0.86)$ \\
Placements $\times$ age & & $0.39^{* * *}(0.054)$ & $0.42^{* * *}(0.072)$ \\
& No $\times$ age & Ref. & Ref. \\
& 1 or $2 \times$ age & $0.0013(0.024)$ & $0.029(0.029)$ \\
& 3 or more $\times$ age & $0.020(0.057)$ & $0.025(0.0036)$ \\
\hline
\end{tabular}

From the final multilevel models, the fixed parameter of placement and age is shown. No interaction effects with placements were found. Other parameters of the final models are not presented

$S E$ Standardized error

${ }^{*} p<0.05,{ }^{* *} p<0.01, * * * p<0.001$

severity of neglect (respectively $p=0.046$ and $p=0.043$ ). Furthermore, trajectories of withdrawn problems differed significantly between adoptees with one or two placements versus those with three or more placements $(p=0.036)$. However, because we tested 21 models, a significance level of $p=0.0024$ would be required after a Bonferroni correction is used. Hence, no interaction effect of syndrome scales and age reached significance after correction for multiple testing.

When we additionally adjusted our analyses for variables encompassing social functioning, only minor changes were found.
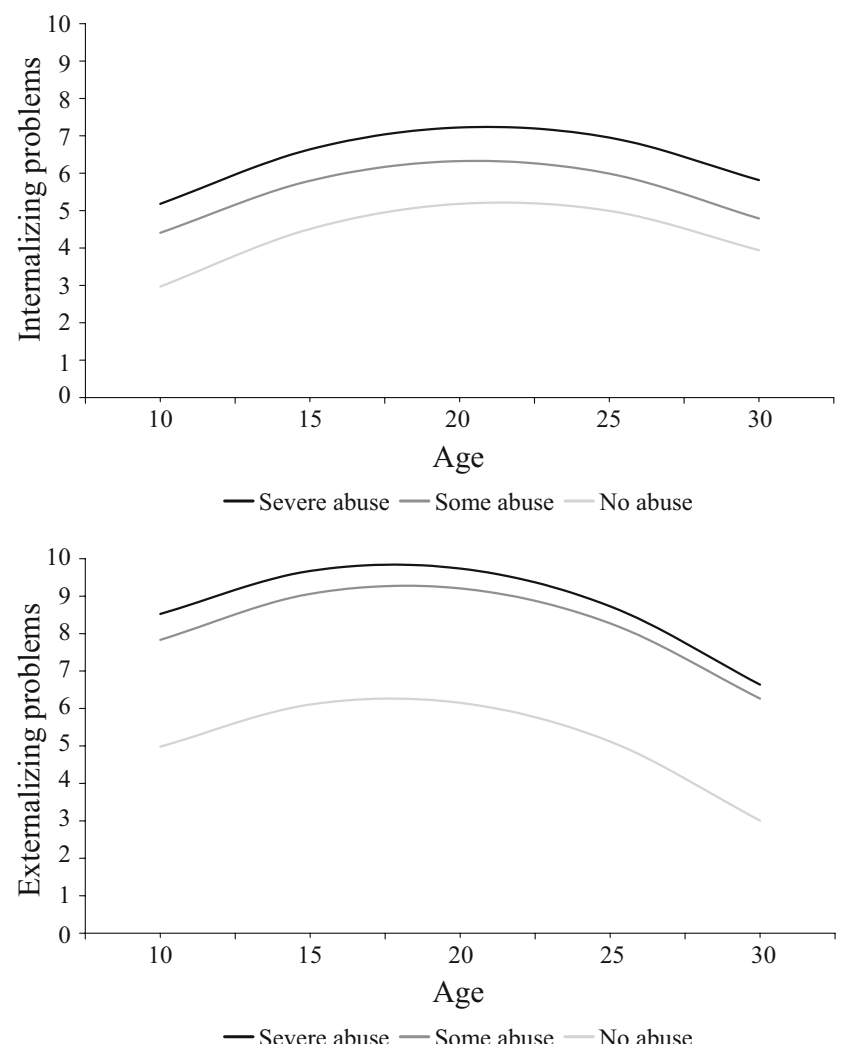

Fig. 2 Internalizing and Externalizing problem scores of abused versus non-abused participants

\section{Discussion}

Trajectories of Psychiatric Problems in Maltreated Children

In the present study, we found that trajectories of psychiatric problems from childhood into adulthood were determined by abuse, neglect and, to a lesser extent, number of placements prior to adoption. Consistently, more severe forms of early adversities were associated with higher levels of psychopathology. Contrary to our hypothesis, the impact of early adversities on internalizing as well
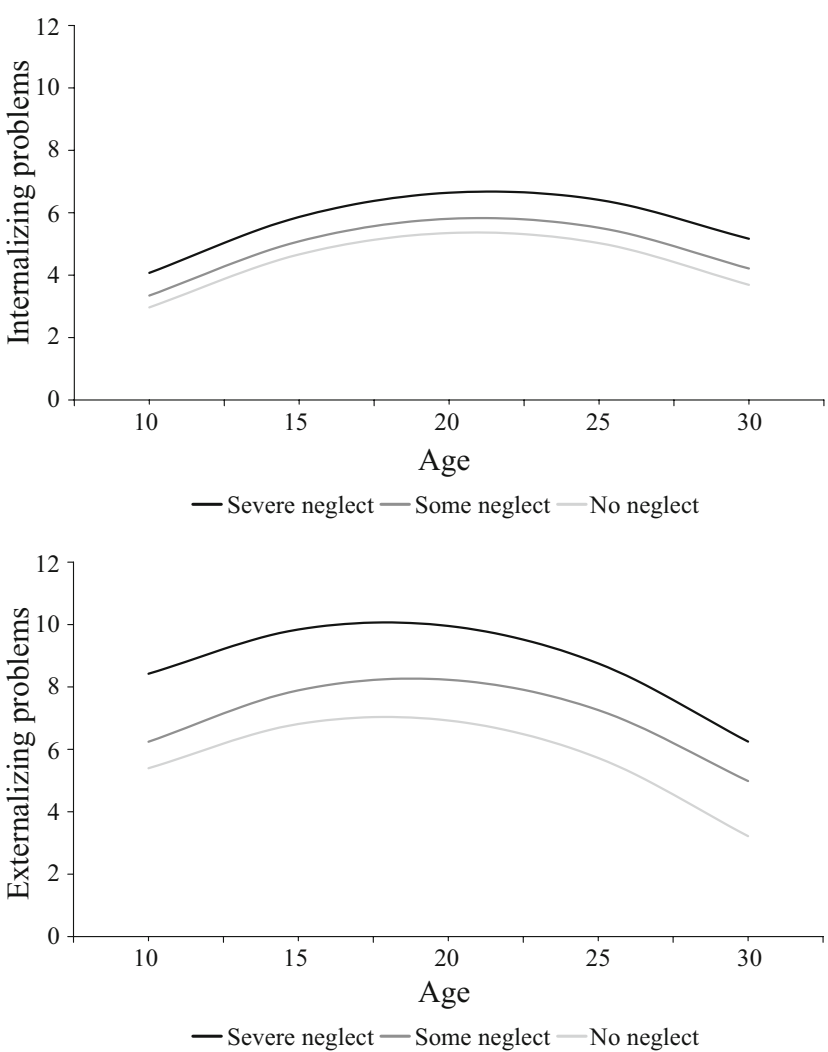

Fig. 3 Internalizing and Externalizing problem scores of neglected versus non-neglected participants 
as externalizing problems did not substantially decrease from childhood to adulthood. Likewise, when the subscale level was studied, the development of more specific psychopathology across the age span was not modified by time. The impact of early adversities on psychiatric problems remained markedly stable over 20 years. Social functioning does not seem to explain results. On the one hand, our results seem to confirm several studies, which found that early adversities have long-term effects on the level of psychiatric problems (e.g., Keiley et al. 2001; Lansford et al. 2002; Trickett and McBride-Chang 1995; Tyler 2002). For example, Cederblad et al. (1999), studying mainly adoptees from Korea, India, and Colombia, showed an association between duration of care in an orphanage or foster home and mental health problems. Hoksbergen (1997) found that there was an increased risk of disruption and residential care in children adopted from Thailand, who had lived in an orphanage or had experienced several changes of caretaking places. Furthermore, several longitudinal studies on the impact of maltreatment on the development of psychopathology into childhood or adolescence have found lasting effects (e.g., Cicchetti and Rogosch 1997; Éthier et al. 2004; Keiley et al. 2001). To our knowledge, the study by Keiley et al. (2001) is the only study in which trajectories of psychiatric problems were determined using multilevel analyses. In accordance with our results, in their non-adopted sample they found that the impact of early physical abuse was fairly stable from childhood into young adolescence assessed by reports of mothers and teachers. Keiley et al. (2001) did observe modification of early adversity by time; children harmed early had a higher and more stable level of mother-reported externalizing behaviors than children that were harmed later in life or were not harmed at all. In line with findings in some other studies of international adoptees, only a small proportion of participants struggle with clinically relevant problems, although these problems can persist into adulthood (Juffer and Van IJzendoorn 2005).

On the other hand, the results of the present study are not compatible with some other studies on childhood adversities. In late childhood, emotional and behavioral disturbances were not clearly associated with early deprivation, in a group of early institutionalized Romanian adoptees (Colvert et al. 2008; Kreppner et al. 2007; Rutter et al. 2001). Possibly, the children in this study were too young to measure particular sequelae. Furthermore, in non-adopted samples Thornberry et al. (2001) found few effects of early adversities in adolescence. And in a cross-sectional study, Kessler et al. (1997) found indications for a reduction of psychiatric problems after childhood adversities over a long period of time. In the present study, we did find some modification by age when the subscale level was studied, which we attributed to chance. However, a Bonferonni correction is overly conservative for these interaction tests and therefore a careful speculation is justified about the different patterns of specific problem dimensions in relation to early maltreatment. Only in one syndrome scale the effect of one or two placements on withdrawn problems seemed to decline to some extent. With respect to thought problems and attention problems, the gap between severe maltreated and moderately or non-maltreated adoptees even increased. Thus, although these results could be based on chance, it is useful to additionally study specific problem dimensions because different patterns between syndrome scales could remain unnoticed when studying broadband scales.

Why was the Hypothesized Decrease of the Impact of Early Adversities Not Found?

The question arises why no reduction in the impact of early maltreatment over a longer period of time, from childhood into adulthood, was found in our study. Several possible explanations can be given.

First, the timing of the adversities could be important. In our sample, participants experienced adversities prior to adoption, which occurred at a mean age of 29 months. Therefore, the adversities were experienced at a young age. This contrasts with the sample studied by Kessler et al. (1997), in which participants experienced adversities before the age of 16 years. It has repeatedly been observed that in particular adversities that occur very early in life have profound and long-lasting effects on psychiatric problems (Carlson et al. 1997; Keiley et al. 2001). This could be due to permanent changes after the experience of early adversities, with the main influence deriving from a lasting effect on somatic structure and function (Rutter et al. 2004). For example, effects of early adversities are associated with alterations in the brain, including the emergence of epileptiform electroencephalogram (EEG) abnormalities, a reduced volume or diminished synaptic density in the hippocampus, and changes in the corpus callosum (see for a review: Teicher et al. 2006). Furthermore, changes in the hypothalamic-pituitary-adrenocortical (HPA) system are found after early maltreatment (Gunnar and Vazquez 2006; Rutter et al. 2004; Teicher et al. 2006).

Second, not only are early adversities common in an internationally adopted sample (Gunnar et al. 2000; Verhulst et al. 1992), the severity of the experiences could also be more profound in comparison to other samples. Prior to adoption, many of the participants in the present study lived under dreadful circumstances, as several adoptees were underfed, had somatic complaints or lacked emotional warmth. In addition, prenatal conditions might also be less favorable in some of the early-maltreated adoptees. This is likely to contrast with the experiences of a 
non-adopted samples described in the studies of Kessler et al. (1997) and Thornberry et al. (2001). If adversities in these samples were less harsh, this could explain the decline of the impact of the adversities with time.

Third, the age at measurement can explain the different findings. In the present study, the high prevalence of psychiatric problems in maltreated individuals persisted from approximately age 10 to 30 years. No information was available to study the impact of early adversities on psychiatric problems prior to this period. It is conceivable that a decline in the risk associated with early adversities occurred only prior to the age of 10 years and not in the age span covered by our study. This would be compatible with the catch-up found in a study of Romanian children adopted into the UK which were followed-up till the age of 11 years (Colvert et al. 2008; Rutter et al. 2001). However, improvements in that study were seen in specific areas only, for example height, growth, cognitive level and atypical behavior. Furthermore, there were also some lasting effects found, mainly in children who were deprived more than 6 months and emotional difficulties increased in early adolescence (Beckett et al. 2002; Beckett et al. 2006; Colvert et al. 2008; Rutter and the ERA Study Team 1998).

Finally, results might be different if more specific factors of the maltreating environment had been studied. Although the inclusion of variables covering social functioning at time 3 did not change results substantially, Lansford et al. (2006), for example, found different trajectories for physically abused in comparison with non-abused children when a vulnerability or protective factor was taken into account. Furthermore, some other factors that may have contributed to later psychiatric problems could not be adjusted for in the present study. For example, information about psychiatric therapy might have enhanced results.

\section{Influence on Trajectories from Gender}

The literature on the modifying effect of gender on the relationship between childhood adversities and psychiatric problems in childhood, adolescence or adulthood is inconsistent, with study results ranging from no gender differences to a larger impact of early maltreatment in either males or females (e.g. Trickett and McBride-Chang 1995; Tyler 2002). To our knowledge, studies of trajectories on psychiatric problems due to early adversities have not addressed modification by gender. In the present study, the impact of early adversities on psychiatric problems was largely independent of gender.

\section{Strengths and Limitations}

The present study is unique in several ways. We were able to study the specific effects of early adversities on later psychiatric problems in a large sample of international adoptees. Many of the participants experienced early adversities and all were subsequently taken out of their problematic environment and raised in better rearing circumstances. Although variability of backgrounds was high in the internationally adopted group, we could make a within-group comparison of the impact of early adversities on psychopathology. Other strengths are that we followed a large sample from childhood to adulthood and used standardized instruments to assess psychiatric problems repeatedly.

Several limitations of the data presented must also be discussed. First, information on early adverse experiences prior to adoption and the severity of these experiences was obtained by asking adoptive parents a single question per adversity. The retrospective nature of the question may have introduced reporting bias (Horwitz et al. 2001). Although we tried to minimize the impact of this phenomenon by excluding adoptees whose parents were not certain about this specific information, we cannot rule out that the degree of certainty was based on other criteria than documented events or physical signs and symptoms. While reverse causality is not likely because the maltreatment was assessed at baseline (mean age of 12 years) and psychopathology repeatedly from the mean age of 12 years to the mean age of 30 years, a carry-over effect is still conceivable. Furthermore, more specific information about maltreatment (e.g., frequency, duration, age of onset, perpetrator type) could have enhanced the results (English et al. 2005). In addition, for 164 children no certain information on the three early adversities was available.

Second, an enriched environment after adoption was assumed, but was not measured. However, in a study of a subgroup of the present sample, self-reports of recalled parental rearing did not change the relationship between early adversities and incident psychiatric disorders in adulthood substantially (unpublished data). In addition, when the adjustment and catch-up after adoption was studied in early institutionally deprived children from Romania, it was found that the outcome was not associated with variations in quality of the adoptive home (Colvert et al. 2008).

Third, although the response rates at each measurement were satisfactory, information on all assessments is available in only half of the participants. Participants tend to be lost to follow-up if psychosocial problems increase. However, in order to bias results, this loss to follow-up has to be associated with early maltreatment. Although this is conceivable, it is not very likely as, overall, maltreatment was not related to loss to follow-up. As a consequence of this limitation, the correction for possible confounding was diminished as variables about social functioning were only applicable at time 3. Data on social functioning was 
missing in a considerable number of participants who had participated only in prior examination rounds.

Finally, the present study used parent reported information; however the relationship between parents and children was not assessed. In particular internalizing problems may not be accurately assessed through this informant, specifically in older age groups. However, several studies have found that self-ratings as well as the ratings of other informants independently predict aspects of psychopathology, such as major depression and psychosocial functioning (Kendler and Roy 1995; Lara et al. 1997) and the correlation between reports of the parents and the adoptees was higher than the correlation found in other studies between different raters (Van der Ende 1999).

\section{Conclusion and Clinical Implications}

Experiencing abuse, neglect or multiple placements prior to adoption influences the level of psychiatric problems throughout childhood, into adolescence and adulthood, with highest problems when maltreatment was most severe. The effects of early adversities seem not to be transient or to decrease in strength, even if adversities are limited to an early period in life and children are taken out of their problematic environments and raised in better circumstances. This suggests that children who experienced early adversities, especially severe maltreatment, and suffer from psychiatric problems at some point in time may need long term mental health care.

Acknowledgements This research was supported by a grant from the Dutch Ministry of Justice (OE-404/1.98). Additional funding was obtained from the Sophia Foundation for Medical Research (SSWO-2002-427).

Open Access This article is distributed under the terms of the Creative Commons Attribution Noncommercial License which permits any noncommercial use, distribution, and reproduction in any medium, provided the original author(s) and source are credited.

\section{References}

Achenbach, T. M. (1991). Manual for the child behavior checklist/4-18 and 1991 profile. Burlington: University of Vermont, Department op Psychiatry.

Achenbach, T. M. (1997). Manual for the young adult self-report and young adult behavior checklist. Burlington: University of Vermont, Department of Psychiatry.

Beckett, C., Bredenkamp, D., Castle, J., Groothues, C., O’Connor, T. G., \& Rutter, M. (2002). Behavior patterns associated with institutional deprivation: a study of children adopted from Romania. Journal of Developmental and Behavioral Pediatrics, 23, 297-303.

Beckett, C., Maughan, B., Rutter, M., Castle, J., Colvert, E., Groothues, C., et al. (2006). Do the effects of early severe deprivation on cognition persist into early adolescence? Findings from the English and Romanian adoptees study. Child Development, 77, 696-711.

Bongers, I. L., Koot, H. M., Van der Ende, J., \& Verhulst, F. C. (2003). The normative development of child and adolescent problem behavior. Journal of Abnormal Psychology, 112, 179-192.

Boyle, M. H., \& Willms, J. D. (2001). Multilevel modelling of hierarchical data in developmental studies. Journal of Child Psychology and Psychiatry, 42, 141-162.

Carlson, E. B., Furby, L., Armstrong, J., \& Schlaes, J. (1997). A conceptual framework for the long-term psychological effects of traumatic childhood abuse. Child Maltreatment, 2, 272-295.

Cederblad, M., Höök, B., Irhammar, M., \& Mercke, A. M. (1999). Mental health in international adoptees as teenagers and young adults. An epidemiological study. Journal of Child Psychology and Psychiatry, 40, 1239-1248.

Cicchetti, D., \& Rogosch, F. A. (1997). The role of self-organization in the promotion of resilience in maltreated children. Development and Psychopathology, 9, 797-815.

Colvert, E., Rutter, M., Beckett, C., Castle, J., Groothues, C., Hawkins, A., et al. (2008). Emotional difficulties in early adolescence following severe early deprivation: Findings from the English and Romanian adoptees study. Development and Psychopathology, 20, 547-567.

Costello, E. J., Compton, S. N., Keeler, G., \& Angold, A. (2003). Relationships between poverty and psychopathology: A natural experiment. JAMA, 290, 2023-2029.

De Jong, A., \& Van der Lubbe, P. M. (2001). Groningse Vragenlijst over Sociaal Gedrag: Zelfbeoordelingsvragenlijsten voor het vaststellen van problemen in het interpersoonlijk functioneren [Groningen Questionnaire about Social Behavior: Self-report questionnaires to determine problems in interpersonal functioning]. Groningen: Rob Giel Onderzoekcentrum.

English, D. J., Upadhyaya, M. P., Litrownik, A. J., Marshall, J. M., Runyan, D. K., Graham, J. C., et al. (2005). Maltreatment's wake: the relationship of maltreatment dimensions to child outcomes. Child Abuse and Neglect, 29, 597-619.

Éthier, L. S., Lemelin, J. P., \& Lacharité, C. (2004). A longitudinal study of the effects of chronic maltreatment on children's behavioral and emotional problems. Child Abuse and Neglect, 28, 1265-1278.

Fensbo, C. (2004). Mental and behavioural outcome of inter-ethnic adoptees: A review of the literature. European Child \& Adolescent Psychiatry, 13, 55-63.

Fergusson, D. M., Horwood, L. J., \& Lynskey, M. T. (1996). Childhood sexual abuse and psychiatric disorder in young adulthood: II. Psychiatric outcomes of childhood sexual abuse. Journal of the American Academy of Child \& Adolescent Psychiatry, 35, 1365-1374.

Fisher, L., Ames, E. W., Chisholm, K., \& Savoie, L. (1997). Problems reported by parents of Romanian orphans adopted to British Columbia. International Journal of Behavioral Development, 20, 67-82.

Gunnar, M. R., Bruce, J., \& Grotevant, H. D. (2000). International adoption of institutionally reared children: Research and policy. Development and Psychopathology, 12, 677-693.

Gunnar, M. R., \& Vazquez, D. (2006). Stress neurobiology and developmental psychopathology. In D. Cicchetti, \& D. J. Cohen (Eds.), Developmental psychopathology (Vol. 2 Developmental neurosciences (2nd edn.), pp. 533-577). New York: Wiley.

Heijmens Visser, J. H., Van der Ende, J., Koot, H. M., \& Verhulst, F. C. (2000). Predictors of psychopathology in young adults referred to mental health services in childhood or adolescence. British Journal of Psychiatry, 177, 59-65.

Hillegers, M. H., Burger, H., Wals, M., Reichart, C. G., Verhulst, F. C., Nolen, W. A., et al. (2004). Impact of stressful life events, familial loading and their interaction on the onset of mood disorders: study in 
a high-risk cohort of adolescent offspring of parents with bipolar disorder. British Journal of Psychiatry, 185, 97-101.

Hoksbergen, R. A. C. (1997). Turmoil for adoptees during their adolescence. International Journal of Behavioral Development, 20, 33-46.

Horwitz, A. V., Widom, C. S., McLaughlin, J., \& White, H. R. (2001). The impact of childhood abuse and neglect on adult mental health: A prospective study. Journal of Health \& Social Behavior, 42, 184-201.

Hudson, C. G. (2005). Socioeconomic status and mental illness: Tests of the social causation and selection hypotheses. American Journal of Orthopsychiatry, 75, 3-18.

Juffer, F., \& Van IJzendoorn, M. H. (2005). Behavior problems and mental health referrals of international adoptees: A meta-analysis. JAMA, 293, 2501-2515.

Keiley, M. K., Howe, T. R., Dodge, K. A., Bates, J. E., \& Petti, G. S. (2001). The timing of child physical maltreatment: A crossdomain growth analysis of impact on adolescent externalizing and internalizing problems. Development and Psychopathology, $13,891-912$.

Kendler, K. S., \& Roy, M. A. (1995). Validity of a diagnosis of lifetime major depression obtained by personal interview versus family history. American Journal of Psychiatry, 152, 1608-1614.

Kessler, R. C., Davis, C. G., \& Kendler, K. S. (1997). Childhood adversity and adult psychiatric disorder in the US National Comorbidity Survey. Psychological Medicine, 27, 1101-1119.

Kreppner, J. M., Rutter, M., Beckett, C., Castle, J., Colvert, E., Groothues, C., et al. (2007). Normality and impairment following profound early institutional deprivation: A longitudinal follow-up into early adolescence. Developmental Psychology, 43, 931-946.

Lansford, J. E., Dodge, K. A., Pettit, G. S., Bates, J. E., Crozier, J., \& Kaplow, J. (2002). A 12-year prospective study of the long-term effects of early child physical maltreatment on psychological, behavioral, and academic problems in adolescence. Archives of Pediatrics and Adolescent Medicine, 156, 824-830.

Lansford, J. E., Malone, P. S., Stevens, K. I., Dodge, K. A., Bates, J. E., \& Pettit, G. S. (2006). Developmental trajectories of externalizing and internalizing behaviors: Factors underlying resilience in physically abused children. Development and Psychopathology, 18, 35-55.

Lara, M. E., Ferro, T., \& Klein, D. N. (1997). Family history assessment of personality disorders: II. Association with measures of psychosocial functioning in direct evaluations with relatives. Journal of Personality Disorders, 11, 137-145.

Marcovitch, S., Goldberg, S., Gold, A., Washington, J., Wasson, C., Krekewich, K., et al. (1997). Determinants of behavioural problems in Romanian children adopted in Ontario. International Journal of Behavioral Development, 20, 17-31.

Mullen, P. E., Martin, J. L., Anderson, J. C., Romans, S. E., \& Herbison, G. P. (1996). The long-term impact of the physical, emotional, and sexual abuse of children: A community study. Child Abuse and Neglect, 20, 7-21.

Rutter, M. L., Kreppner, J. M., \& O’Connor, T. G. (2001). Specificity and heterogeneity in children's responses to profound institutional privation. British Journal of Psychiatry, 179, 97-103.

Rutter, M., \& O'Connor, T. G. (2004). Are there biological programming effects for psychological development? Findings from a study of Romanian adoptees. Developmental Psychology, 40, 81-94.
Rutter, M., \& the ERA Study Team (1998). Developmental catch-up, and deficit, following adoption after severe global early privation. Journal of Child Psychology and Psychiatry, 39, 465-476.

Simmel, C. (2007). Risk and protective factors contributing to the longitudinal psychosocial well-being of adopted foster children. Journal of Emotional and Behavioral Disorders, 15(4), 237249.

Simmel, C., Barth, R. P., \& Brooks, D. (2007). Adopted foster youths? Psychosocial functioning: A longitudinal perspective. Child and Family Social Work, 12(4), 336-348.

Surtees, P. G., \& Wainwright, N. W. (1999). Surviving adversity: event decay, vulnerability and the onset of anxiety and depressive disorder. European Archives of Psychiatry and Clinical Neuroscience, 249, 86-95.

Teicher, M. H., Tomoda, A., \& Andersen, S. L. (2006). Neurobiological consequences of early stress and childhood maltreatment: are results from human and animal studies comparable? Annals of the New York Academy of Sciences, 1071, 313-323.

Thornberry, T. P., Ireland, T. O., \& Smith, C. A. (2001). The importance of timing: The varying impact of childhood and adolescent maltreatment on multiple problem outcomes. Development and Psychopathology, 13, 957-979.

Tieman, W., Van der Ende, J., \& Verhulst, F. C. (2005). Psychiatric disorders in young adult intercountry adoptees: An epidemiological study. American Journal of Psychiatry, 162, 592-598.

Tieman, W., Van der Ende, J., \& Verhulst, F. C. (2006). Social functioning in young adult intercountry adoptees compared to nonadoptees. Social Psychiatry and Psychiatric Epidemiology, 41, 68-74.

Trickett, P. K., \& McBride-Chang, C. (1995). The developmental impact of different forms of child abuse and neglect. Developmental Review, 15, 311-337.

Tyler, K. A. (2002). Social and emotional outcomes of childhood sexual abuse: A review of recent research. Aggression and Violent Behavior, 7, 567-589.

Van der Ende, J. (1999). Multiple informants: multiple views. In H. M. Koot, A. A. M. Crijnen, \& R. F. Ferdinand (Eds.), Child psychiatric epidemiology. Accomplishments and future directions (pp. 39-52). Assen: Van Gorcum.

Van der Lubbe, P. M. (1995). De ontwikkeling van de Groningse Vragenlijst over Sociaal Gedrag (GVSG) [The development of the Groningen Questionnaire about Social Behavior (GQSB)]. Groningen: Rijksuniversiteit Groningen.

Van Westerlaak, J. H., Kropman, J. A., \& Collaris, J. W. M. (1975). Beroepenklapper [Manual for occupational level]. Nijmegen, The Netherlands: Institute for Applied Sociology.

Verhulst, F. C., Althaus, M., \& Versluis-den Bieman, H. J. (1990). Problem behavior in international adoptees: I. An epidemiological study. Journal of the American Academy of Child \& Adolescent Psychiatry, 29, 94-103.

Verhulst, F. C., Althaus, M., \& Versluis-den Bieman, H. J. (1992). Damaging backgrounds: Later adjustment of international adoptees. Journal of the American Academy of Child \& Adolescent Psychiatry, 31, 518-524.

Verhulst, F. C., Van der Ende, J., \& Koot, H. M. (1996). Handleiding voor de CBCL/4-18 [Manual for the CBCL/4-18]. Rotterdam: Erasmus University, Sophia's Children's Hospital, Department of Child and Adolescent Psychiatry.

Verhulst, F. C., \& Versluis-den Bieman, H. J. (1995). Developmental course of problem behaviors in adolescent adoptees. Journal of the American Academy of Child \& Adolescent Psychiatry, 34, 151-159. 